Running title: Byles J. Fit and well.

\title{
Fit and Well at 80: Defying the stereotypes of age and illness
}

Julie E Byles BMed. PhD. AAG Fellow.

Director, Research Centre for Gender, Health and Ageing (RCGHA).

The University of Newcastle, NSW, Australia.

\author{
Author address: \\ Professor Julie Byles \\ Director, Research Centre for Gender, Health and Ageing (RCGHA). \\ The University of Newcastle, c/- Room 266, DMB, Royal Newcastle Hospital. \\ Phone +61 2 49236643, Fax +61 2 49236148, E-mail: Julie.Byles@newcastle.edu.au
}

Acknowledgements: The Australian Longitudinal Study on Women's Health was developed by groups of inter-disciplinary researchers at the Universities of Newcastle and Queensland, and is funded by the Australian Department of Health and Ageing. We thank all participants for their valuable contribution to this project.

Professor Byles is a member of the Hunter Medical Research Institute.

Key words. Ageing, quality of life, longitudinal studies.

Word count: 3906

\begin{abstract}
While ageing is associated with physical decline and increased risk of illness, older age is not inevitably a time of ill-being. Data from the Australian Longitudinal Study on Women's Health challenge negative stereotypes of ageing and illness. While an accelerating decline in average physical health was observed over the first six years of the study, an important and large proportion of the women experienced minimal change in their physical health in this period. Also, while chronic disease was a strong risk factor for declining health, many women aged well in spite of longstanding medical conditions. This paper presents trends in health and illness as women age and explores some of the many physical, social, and health care factors that mark out those women who remain "fit and well".
\end{abstract}




\section{Ageing, illness, and quality of life}

As people age they have increased risk of disease and disability. Busse ${ }^{1}$ described ageing as an accumulation of the impact of time, environmental factors, and disease. These factors are not independent. Changes of ageing can also be considered in terms of physiology, disease, and social changes. Physiological changes of ageing affect all body systems, and can limit reserve, reduce ability to maintain homeostasis, and increase potential for illness. ${ }^{2}$ Consequently, older people have a higher incidence and prevalence of many conditions. These include conditions that are rapidly fatal (such as lung cancer) and which contribute greatly to loss of years of life, and those that are chronic and associated with loss of quality of life.

Ischaemic heart disease and cerebrovascular disease are leading causes of disability and death among people aged 60 years and over. Other major causes of disability and death in this age group include chronic obstructive lung disease, dementias, vision disorders, and cancers. Older people are also particularly vulnerable to respiratory infections such as pneumonia. Hearing loss is a major cause of disability that is highly prevalent and has significant impact on quality of life. Likewise, musculoskeletal conditions are common among older people and contribute to disability. ${ }^{3}$ These common conditions are associated with a range of functional limitations such as cognitive impairment, mobility restrictions, and urinary incontinence.

In addition, older adults have many active health problems that interact with each other and complicate approaches to treatments. In one study of men and women aged 70 years and over, the median number of conditions per person was $7 .^{4}$ This multimorbidity has been shown to be associated with health outcomes such as quality of life, activities of daily living, health service utilisation and mortality.

Social circumstances add to the difficulties that people face as they age and social inequity is one of the major determinants of ill health at all ages. ${ }^{5}$ Poor circumstances have their first impact during pregnancy, when deficiencies in nutrition, maternal stress, smoking and misuse of drugs and alcohol, insufficient exercise and inadequate prenatal care can inhibit optimal foetal development. The impact of disadvantage continues throughout childhood and adult life and is manifest in terms of psychosocial stress, poor education, poor nutrition, social exclusion, underemployment and poor job security, and work-related stress and injury. Smoking, alcohol and drug use are also higher among people in disadvantaged circumstances. Disadvantaged people also tend to live in poorer neighbourhoods with high rates of violence and crime, in overcrowded circumstances, and potentially in areas with high levels of environmental toxins.

Social support is another social factor that affects wellbeing at older age. A number of studies have demonstrated association between social support and improved survival, reduced disability and health care use, and improved quality of life. ${ }^{6} 89$ It is thought that these health effects are mediated through the influence of social support on health behaviour, improved access to care, and possibly through effects in physiological pathways.

\section{Measuring Health in Older Age}

Early research into ageing has focussed on survival and longevity. More recently great attention has been given to the quantification of quality of life as a measure of general health status. Quality of life in older age is affected not only by disease but also by symptoms which may not be associated with specific pathology, and by social circumstances. Common symptoms include joint stiffness, 
constipation, incontinence, memory complaints. However, despite the presence of symptoms, medical conditions and disability older people often report their health as good, very good or excellent, and record high quality of life scores. Likewise, while disease is a common but not inevitable consequence of longevity, disease does not always equal "poor health".

\section{Longitudinal Studies of health and ageing}

In the last century serious old age has become an increasingly expected and predictable part of life and the desire to understand and influence the process and effects of ageing has escalated exponentially. The National Institutes of Health database of longitudinal studies includes 54 studies that they consider represent "research initiatives for identifying the physiologic and other types of factors across the lifespan, affecting onset and progression of disease with advancing age, as well as elucidation of protective factors contributing to exceptionally healthy aging." ${ }^{10}$ One reason for conducting longitudinal studies is to understand trajectories of ageing - with and without disability and disease. ${ }^{11}$ The aim is to be able to identify the risk of disability among older people, and to understand the impact and natural history of disease in later life.

\section{The Australian Longitudinal Study on Women's Health: Evidence to defy the stereotypes of ageing:}

The Australian Longitudinal Study of Women's Health (ALSWH) is a population-based study of changes in the health of a national sample of women in three age cohorts (aged 18-23, 45-50 and 70-75 in 1996). The study was designed to investigate multiple factors affecting health and well being of women over a 20-year period. Participants in the study were randomly selected from the national Medicare database which contains name and address details of all Australian citizens and permanent residents. This database is widely regarded as the most up-to-date and complete list of Australians in existence. Further details of the study have been published elsewhere. ${ }^{12}$

The women in the older cohort were aged 70-75 years at the time of the first postal survey in 1996 and have since been invited to complete three follow-up surveys - Survey 2 in 1999 (S2), Survey 3 in 2002 (S3), and Survey 4 in 2005 (when the women were aged 79-84 years). Each survey included many questions about the women's health and lifestyle. Withdrawals and reasons for withdrawal are recorded, and deaths are checked through the National Death Index.

The 1996 baseline data provided by the older cohort provided a "picture of ageing that challenges negative stereotypes of frailty and declining well being". ${ }^{13}$ At the time of that survey the women were aged 70-75 and the women are now into their 80s. They have provided longitudinal data on a wide range of physical, psychological, social and health service usage variables which allow a comprehensive view of how ageing has affected this large cohort of women. This paper presents the magnitude and variation in change in physical function for the women who continued to participate in the first six-years of the study (S1-S3).

\section{Main measures of health and function}

The Medical Outcomes Study 36-item Short Form Health Survey (SF-36) ${ }^{14} 15$ is a generic profile measure which examines self-reported health-related quality of life. The SF-36 is a widely used and 
well validated health profile that has been extensively reviewed for use with older populations. A recent structured review of generic self-assessed instruments for older people identified the SF-36 as one of three instruments with extensive evidence of internal consistency, test-retest reliability, construct validity, concurrent validity and responsiveness. ${ }^{16}$ The SF-36 is recommended where a detailed and broad ranging assessment of health is required, particularly in community dwelling older people. The SF-36 produces eight sub-scales and two summary scores (Physical Components Summary score (PCS) and Mental Health Components Score). A low score on the PCS reflects limitations in physical, social, and role activities, severe bodily pain, frequent tiredness and "poor" self-rated health.

Other measures of health included in the surveys are:

- $\quad$ Self-reported diagnoses (arthritis, diabetes, heart disease, hypertension, stroke, thrombosis, low iron level, asthma, bronchitis/emphysema, osteoporosis, cancer, depression, anxiety, Alzheimer's/dementia);

- $\quad$ Falls and injuries;

- $\quad$ Days spent in hospital in past twelve months;

- $\quad$ Satisfaction with physical ability (measured using an item taken from the SF-36 Physical Functioning measure; ${ }^{17}$

- $\quad$ Self-reported symptoms (breathing difficulty, chest pain, tiredness, stiff or painful joints, back pain, foot problems, dysuria, nocturia, urinary urgency; incontinence, constipation, poor memory, clumsiness, dizziness);

- $\quad$ Vision (difficulty reading a newspaper even with glasses);

- $\quad$ Hearing (difficulty hearing a conversation);

- $\quad$ Items from the Centre for Epidemiological Studies Depression scale (CESD); ${ }^{18}$

- $\quad$ Physical activity;

- $\quad$ Body mass index (BMI);

- $\quad$ Nutrition risk; ${ }^{19}$

- $\quad$ Stress about health, living arrangements and relationships;

- $\quad$ Items from the abbreviated Duke's Social Support Index (DSSI); ${ }^{20}$

- $\quad$ Ability to use public transport;

- $\quad$ Availability of instrumental support; ${ }^{21}$

- $\quad$ Attitudes to life including optimism and hardiness. ${ }^{22}$

Full details of all measures are available at www.alswh.org.au.

\section{Six Year Change in Health and Function}

Survey 1 included 12,432 women, who were aged 70-75 years at that time. There were 10,434 women who remained in the study at S2, and 8,647 women at S3 (69.6\% of the original cohort). Between S1 and S3, 1097 women died (9\%) and a further 363 withdrew because they had become too frail to complete the survey, a further 1487 (9.5\%) withdrew for other reasons, and 838 could not be contacted or otherwise did not complete S3. A total of 8,397 women completed S1, S2, and S3.

The most common symptoms reported by women at all surveys were stiff and painful joints (reported by $67 \%$ of women at S1), back pain (55\%), difficulty sleeping (50\%), eyesight problems (49\%), poor memory (41\%), tiredness (41\%), indigestion (39\%), allergies (35\%), headaches (32\%), constipation (28\%). There were few differences between reported prevalence of symptoms at S1 and S3. There were small percentage increases in the prevalence of difficulties with hearing (increasing from $11 \%$ at S1 to $13 \%$ at S3) and vision (14\% at S1, $17 \%$ at S3). ${ }^{23}$ Prevalence of conditions increased with age. 
For instance, the prevalence of heart disease was $17 \%$ at S1 and increased to $24 \%$ by S3. Likewise, $9 \%$ of the women reported having diabetes at S1 and this proportion increased to $12 \%$ at S3. Arthritis was reported by $41 \%$ of the women at $\mathrm{S} 2$ and $60 \%$ at $\mathrm{S} 3 .^{24}$

The period prevalence of falls did not change with around 18\% falling within the past year at each survey. At S1, $41 \%$ of the women were taking three or more medications. This percentage increased to $51 \%$ at S2, and $60 \%$ at S3. Few older women smoked (4.7\% at S2) or drank more than two standard alcoholic drinks per day ${ }^{25}$ (4.1\% at S2). At S2 around 30\% of women were taking no exercise compared to about $40 \%$ at S3; the percentage of women undertaking moderate exercise every day of the week was $40 \%$ at $\mathrm{S} 2$ and $34 \%$ at $\mathrm{S} 3 .^{23}$

The percentage regularly needing help with daily tasks increased from 5\% at Survey 1 to $13 \%$ at S3. The percentage providing regular care or assistance to another person increased from $19 \%$ at Survey 1 to $24 \%$ at Survey 3 . $^{23}$

SF-36 scores for women who had completed S1, S2, and S3 are presented in Table 1. Scores declined for most sub-scales, and declined more steeply between S2 and S3 than between S1 and S2. For women who answered all three surveys, mean mental health summary scores were high (51.3, 51.8 and 51.4 at S1, S2 and S3 respectively). However, mean physical health summary scores declined from 51.1 at S1 to 50.0 at S2 and 48.0 at S3. ${ }^{23}$ Variation in the change in PCS between S2 and S3 is shown in Figure 1. Further analysis of the variation in change in SF-36 sub-scale scores reveals three main effects. Depending on the sub-scale, around $20 \%$ of the women had low scores at all three surveys, around 70\% had high scores at all three surveys, and 10\% had high scores at S1 and low scores at S3 (unpublished data).

\section{Factors associated with Survival}

The probability that a woman died between S1 and S2 was strongly associated with living in a rural area, having poor self-rated health, needing meds for chronic illness, and smoking. Being married was protective. ${ }^{26}$ The number of chronic conditions reported by the women was also associated with survival (unpublished data). Women who never or rarely drank alcohol were also more likely to die than women who have one or two drinks each day. ${ }^{27}$ Women with higher socioeconomic status had lower death rates than women in the low SES group (relative risk: 0.79, 95\% confidence interval 0.640.98). ${ }^{28}$ Another $22 \%$ of the original cohort did not die but either withdrew or otherwise failed to provide data for S3. Analysis of reasons for this attrition indicate that compared to women who stayed in the study, these women had poorer health at S1, were more likely to be taking medication for chronic illness, and more likely to be current smokers. They were also more likely to be born overseas, living in a rural area, have difficulty managing on income, and have poor social support. They were less likely to be married. ${ }^{26}$

\section{Factors associated with maintaining high levels of physical health related quality of life.}

We classified women who survived and completed S1, S2 and S3 according to whether their S2 PCS score was above the 1 st quintile (PCS $<40.0)$ or below $(1,665$ women, $24 \%)$. Women with high scores at S2 were further classified as maintaining high scores (4,803 women (68\%), and declining scores between S2 and S3 (557 women, 8\%). A large number of variables were significantly associated with whether women who survived and stayed in the study had high PCS scores at S2 and whether they 
maintained these high scores at S3. Main health factors are shown in Table 2. Those women who maintained high PCS scores had fewer conditions and fewer symptoms at S2. Significant differences between groups were also evident for falls, BMI, satisfaction with physical ability, ability to use public transport, vision and hearing, stress about health, living arrangements and relationships, some items from the abbreviated Duke Social Support Index, all items on instrumental support, optimism and hardiness, nutrition risk and all items from CES-D. ${ }^{29}$

The most common conditions reported by the women and the probability that women with these conditions will have high PCS scores at S2 and maintain these at S3 are shown in Table 3. Women surviving with these conditions are less likely to have and maintain high PCS scores than those without these conditions, although many maintained higher levels of PCS over the three years. Other analyses compared PCS scores for women according to whether they reported a chronic condition at S1 (existing case), reported the condition at S2 or S3, or never reported the condition. Trends in PCS for women defined according to their reporting of arthritis ${ }^{i}$ and heart disease are shown in Figure 2. For both conditions, women who never report the condition have highest PCS scores at all time points. Women classified as existing cases had lowest PCS scores at S1, but women classified as new cases had similarly low PCS scores at S3.

\section{Health Promotion for Older Age}

An understanding of factors associated with successful ageing lends to development of opportunities to promote successful ageing. Longitudinal studies point to the importance of avoiding risk factors such as smoking, getting good nutrition, physical activity, social interaction, being productive and engaged and maintaining a positive outlook. Strategies to promote optimal ageing address the need to operate across the life-course to increase redundancy and durability, avoid damage and improve maintenance and repair at cellular and structural levels, and to enable the individual to adapt and compensate for losses when they occur.

The avoidance of chronic disease appears to be an important factor in ensuring survival and good health in older age. Many risk factors have been shown to have clear and strong association with chronic disease. For example, smoking is a risk factor for cardiovascular disease, stroke, respiratory disease and many cancers, and smoking prevention is important in reducing the incidence of these conditions. $^{30}$ Physical activity is strongly associated with lower rates of cardiovascular disease, depression and osteoporosis in many observational studies. Obesity and overweight are associated with increased risk of stroke, coronary artery disease, diabetes, arthritis and some cancers. ${ }^{31}$ Observational studies suggest a clear association between nutrition and health at older ages. ${ }^{32}$

An analysis of major risk factors in ALSWH showed strong associations between lower levels of education and greater risk of chronic disease in later life. Overweight and obesity were strongly associated with prevalence and incidence of hypertension, heart disease, diabetes, asthma, and with the prevalence of arthritis, and smoking was significantly associated with heart disease, diabetes, asthma and arthritis. A low level of physical activity was associated with hypertension, heart disease, diabetes, osteoporosis, arthritis and asthma. ${ }^{24}$

\footnotetext{
' Arthritis was first asked about in Survey 2. So, for Arthritis, existing cases were reported at S2 and new cases were reported at S3.
} 
These factors are the focus of health promotion campaigns for young people and older adults with the implication that they are within the control of the individual. However, other factors that are outside of the individual are also important and these include genetic factors and socio-economic background.

Among older women in ALSWH, lower education was significantly associated with higher prevalence of hypertension, and with prevalence and incidence of diabetes. ${ }^{24}$ Socioeconomic factors may also influence people's engagement in healthy and unhealthy behaviours throughout life. There is a complex interplay between factors that might be within an individual's power to change, factors that require change at a systems level, and factors that are difficult to change. Thus, while it is useful to highlight behaviours of individuals as risk factors for ill health at later ages, addressing these problems requires that the social circumstances that underpin these behaviours are also accounted for.

Prevention of some conditions would result in a relative increase the ratio of healthy life expectancy to life expectancy. This scenario is predicted for elimination of endocrine, nutritional and metabolic disorders, respiratory and digestive disorders in men, neoplasms in women, and musculoskeletal disorders and mental conditions. ${ }^{33}$ The population effects of preventing a condition such as arthritis would be considerable, since so many individuals are affected. As well as the direct effects of pain and stiffness, arthritis has indirect effects by limiting physical activity and thereby increasing risk of other conditions. Boult et al. ${ }^{34}$ modelled the potential impact of a $0.5 \%$ per annum decrease in prevalence of six chronic conditions, against increasing numbers of older persons. In this model the greatest reductions in the number of people with functional limitations came from decreased prevalence of arthritis, with smaller reductions from decreases in prevalence of confusion, diabetes, and stroke.

However, even if half of the incidence of chronic disease could be prevented, population ageing means that these conditions will become increasingly prevalent. On current evidence, even with the most effective prevention campaigns people still develop chronic conditions in older age. However, much can be done to reduce the impact of conditions on quality of life. Many older people who live with chronic disease manage well, and consider themselves to be healthy long after diagnosis. The role of research into healthy ageing is not only to find ways to prevent disease, but also to find ways to ensure the best possible health for people ageing with chronic disease.

\section{Future research}

The ALSWH continues to collect and analyse data on the three cohorts of women. Plans are currently in place to undertake Survey 5 of the older women in 2008 when the women will be aged 82 to 87 years. The study is planned to continue for at least another ten years until the women are 90-95 years old. As well as being able to describe the changing health of these women, the study will also provide data to determine whether successive cohorts of women are likely to be healthier (or not) as they reach older ages. The need for longitudinal studies on ageing increases as the population ages. The environment in which we grow and age is constantly changing and we cannot only examine "old" data to tell us about our own futures. 
Table 1. Physical and mental health-related subscales of the SF-36 for the same 8,397 women at three different ages*.

\begin{tabular}{|c|c|c|c|c|c|c|c|c|}
\hline \multirow[b]{2}{*}{$\begin{array}{l}\text { Age at each } \\
\text { survey }\end{array}$} & \multicolumn{8}{|c|}{ Mean (95\% confidence interval) } \\
\hline & $\begin{array}{l}\text { Physical } \\
\text { functioning }\end{array}$ & $\begin{array}{l}\text { Physical role } \\
\text { limitations }\end{array}$ & Bodily pain & $\begin{array}{l}\text { General } \\
\text { health }\end{array}$ & Vitality & $\begin{array}{l}\text { Social } \\
\text { functioning }\end{array}$ & $\begin{array}{l}\text { Emotional } \\
\text { role } \\
\text { limitations }\end{array}$ & $\begin{array}{l}\text { Mental } \\
\text { health }\end{array}$ \\
\hline 70-75 years & $\begin{array}{l}66.9 \\
(66.4 ; 67.5)\end{array}$ & $\begin{array}{l}62.4 \\
(61.5 ; 63.3)\end{array}$ & $\begin{array}{l}67.4 \\
(66.8 ; 67.9)\end{array}$ & $\begin{array}{l}68.6 \\
(68.2 ; 69.0)\end{array}$ & $\begin{array}{l}62.5 \\
(62.0 ; 62.9)\end{array}$ & $\begin{array}{l}84.5 \\
(84.0 ; 85.0)\end{array}$ & $\begin{array}{l}80.0 \\
(79.2 ; 80.7)\end{array}$ & $\begin{array}{l}78.8 \\
(78.4 ; 79.1)\end{array}$ \\
\hline 73-78 years & $\begin{array}{l}64.4 \\
(63.9 ; 65.0)\end{array}$ & $\begin{array}{l}58.0 \\
(57.1 ; 58.9)\end{array}$ & $\begin{array}{l}66.1 \\
(65.5 ; 66.7)\end{array}$ & $\begin{array}{l}68.1 \\
(67.6 ; 68.5)\end{array}$ & $\begin{array}{l}59.8 \\
(59.4 ; 60.3)\end{array}$ & $\begin{array}{l}84.3 \\
(83.8 ; 84.8)\end{array}$ & $\begin{array}{l}80.4 \\
(79.7 ; 81.1)\end{array}$ & $\begin{array}{l}79.6 \\
(79.2 ; 79.9)\end{array}$ \\
\hline 76-81 years & $\begin{array}{l}58.4 \\
(57.8 ; 59.1)\end{array}$ & $\begin{array}{l}50.2 \\
(49.3 ; 51.1)\end{array}$ & $\begin{array}{l}62.5 \\
(62.0 ; 63.1)\end{array}$ & $\begin{array}{l}65.9 \\
(65.5 ; 66.4)\end{array}$ & $\begin{array}{l}56.7 \\
(56.2 ; 57.1)\end{array}$ & $\begin{array}{l}78.7 \\
(78.1 ; 79.3)\end{array}$ & $\begin{array}{l}76.6 \\
(75.8 ; 77.4)\end{array}$ & $\begin{array}{l}78.7 \\
(78.3 ; 79.0)\end{array}$ \\
\hline
\end{tabular}

* Weighted to allow for over-sampling of women living in rural and remote areas. Numbers vary due to missing data (0.3\% to $7.9 \%$ ). A higher score indicates better functioning.

Source: Byles J. Powers J. Chojenta C and Warner Smith P. Older Australian Women: Ageing in Urban, Rural and Remote Environments. Australasian Journal of Ageing 2006; 25(3); 151-157. 
Table 2.

Health characteristics at Survey 2 for women

who maintained high PCS scores, women with high scores at S2 and low scores at S3 (declining scores), and women with low score at S2

\begin{tabular}{|c|c|c|c|}
\hline & $\begin{array}{l}\text { Maintained } \\
\text { high PCS S2- } \\
23\end{array}$ & $\begin{array}{l}\text { Declining } \\
\text { PCS S2-S3 }\end{array}$ & $\begin{array}{l}\text { Low PCS at } \\
\quad \text { S2 }\end{array}$ \\
\hline Age: mean (SD) & $75.4(1.5)$ & 75.5 (1.5) & 75.6 (1.5) \\
\hline No. diagnoses (in past 12 months) & $1.3(1.2)$ & $2.0(1.4)$ & $2.5(1.6)$ \\
\hline No. symptoms (in past 12 months) & $8.7(7.4)$ & $14.0(8.6)$ & $17.7(10.0)$ \\
\hline Body Mass Index mean (SD) & $24.8(4.1)$ & $25.8(5.1)$ & $26.7(5.1)$ \\
\hline $\begin{array}{l}\text { Prescription medications ( } \% \text { taking } \\
5 \text { or more in past } 4 \text { weeks) }\end{array}$ & $12 \%$ & $29 \%$ & $46 \%$ \\
\hline $\begin{array}{l}\text { No. GP visits ( }>12 \text { times in past } 12 \\
\text { months) }\end{array}$ & $7 \%$ & $19 \%$ & $30 \%$ \\
\hline Specialist visits (in past 12 months) & $41 \%$ & $56 \%$ & $67 \%$ \\
\hline $\begin{array}{l}\text { Hospital admission (in past } 12 \\
\text { months) (\% yes) }\end{array}$ & $21 \%$ & $31 \%$ & $45 \%$ \\
\hline Been injured from a fall (\% yes) & $10 \%$ & $13 \%$ & $19 \%$ \\
\hline
\end{tabular}

All comparisons shown in Table statistically significant $\mathrm{p}<0.001$ 
Table 3.

Probability of having and maintaining high PCS for women with and without specific conditions at Survey 2

\begin{tabular}{rcc}
\hline & Condition Prevalent at S2 \\
\hline No & Yes \\
Arthritis & $80 \%$ & $54 \%$ \\
Heart disease & $72 \%$ & $45 \%$ \\
Hypertension & $72 \%$ & $62 \%$ \\
Diabetes & $70 \%$ & $51 \%$ \\
Stroke & $69 \%$ & $41 \%$ \\
Low iron level & $70 \%$ & $41 \%$ \\
Asthma & $70 \%$ & $50 \%$ \\
Bronchitis/emphysema & $70 \%$ & $47 \%$ \\
Osteoporosis & $71 \%$ & $51 \%$ \\
Depression & $70 \%$ & $51 \%$ \\
Anxiety/nervous & $69 \%$ & $54 \%$ \\
\hline
\end{tabular}




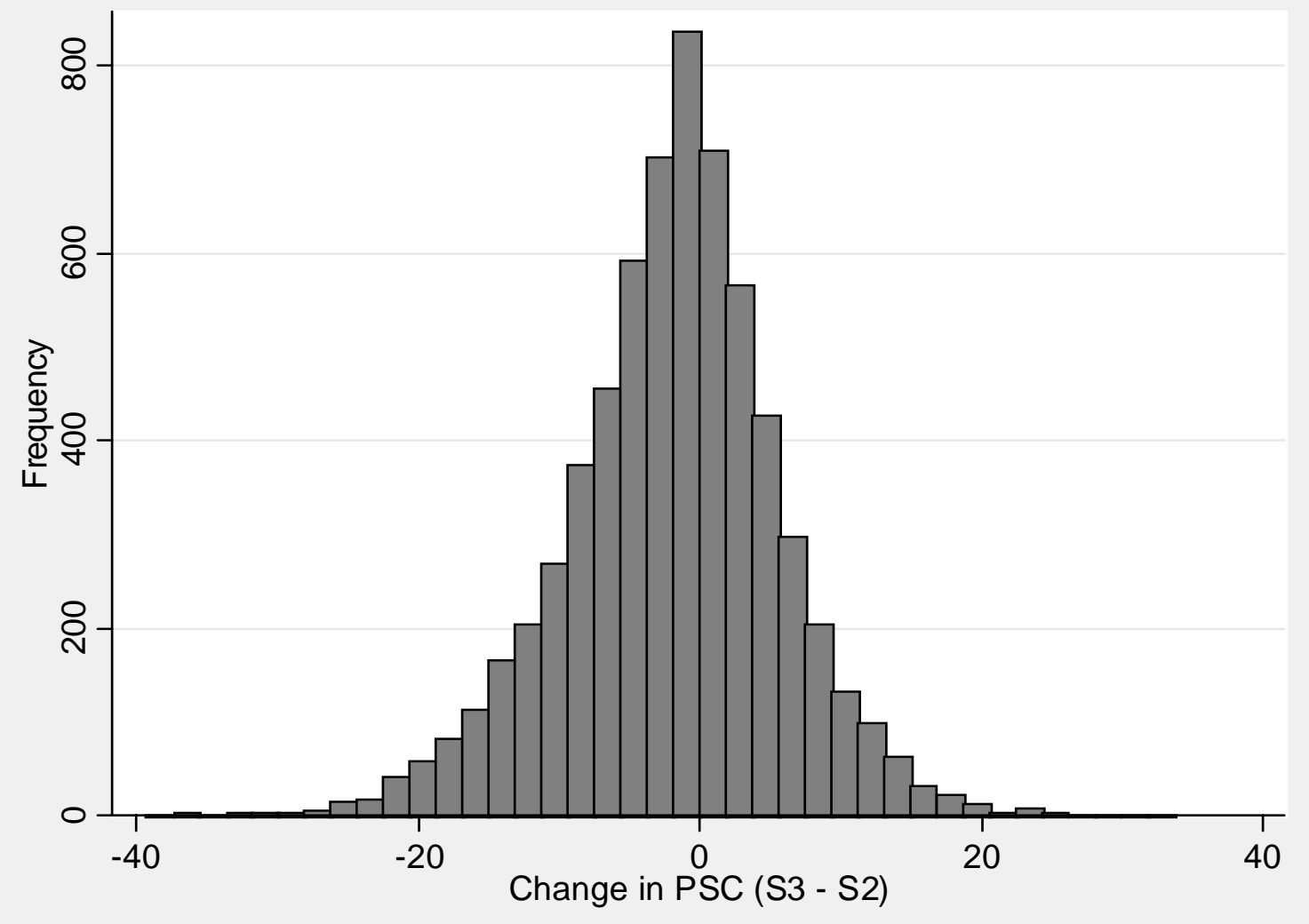

Figure 1

Change in physical functional health score (PCS) from Survey 2 to Survey 3 

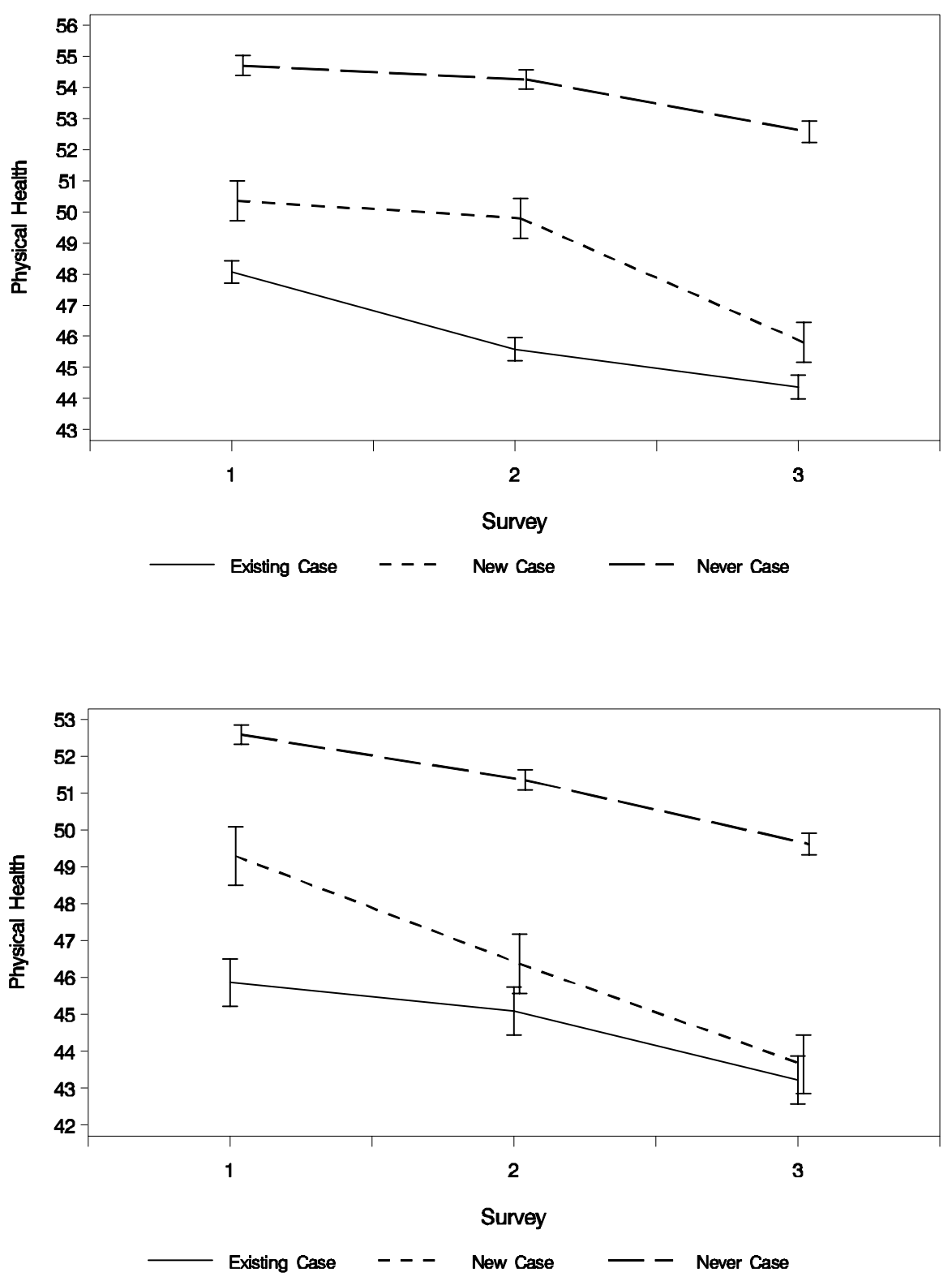

Figure 2

Trends in PCS score for S1, S2, S3 by arthritis and heart disease status. 
${ }^{1}$ Busse, E.W. 1969. Theories of ageing. In Behaviour and adaptation in later life. E.W. Busse \& E. Pfeiffer, Eds.: 11-32. Little Brown. Boston, MA.

${ }^{2}$ Ebrahim, S. 2002. Health of Elderly People. In Oxford Textbook of Public Health, 4th Edn. R. Detels, J. McEwan, R. Beaglehole, \& H. Tanaka, Eds.: Vol. 3, Ch. 11.8. 1712. Oxford University Press. Oxford, UK.

${ }^{3}$ World Health Organisation. The world health report 2003 - shaping the future.

${ }^{4}$ Byles, J.E., et al. 2005. Single index of multimorbidity did not predict multiple outcomes. J Clin Epidemiol. 58(10): 997-1005.

${ }^{5}$ Marmot, M. 2005. Social determinants of health inequalities. Lancet. 365(9464): 1099-1104.

${ }^{6}$ Berkman, L.F \& Syme, S.L. 1979. Social networks, host resistance and mortality: A nine year follow-up study of Alameda County residents. Am J Epidemiol. 109: 186-204.

${ }^{7}$ Bowling, A. \& Browne, P.D. 1991. Social networks, health, and emotional well-being among the oldest old in London. J Gerontol. 46(1): S20-32.

${ }^{8}$ Steinbach, U. 1992. Social networks, institutionalization, and mortality among elderly people in the United States. J Gerontol. 47: 5183-5190

${ }^{9}$ Mendes de Leon, C.P. et al. 1999. Social networks and disability transitions across eight intervals of yearly data in the New Haven EPESE. J Gerontol. 54: S62-72.

${ }^{10}$ National Institutes of Health. National Institute of Ageing Database of Longitudinal Studies. http://www.nia.nih.gov/ResearchInformation/ScientificResources/LongitudinalStudies.htm (last accessed 1 April 2007)

${ }^{11}$ Fozard, J.L., Metter, J. \& Brant, L.J. 1990. Next steps in describing aging and disease in longitudinal studies. J Gerontol. 45(4): 116-127.

${ }^{12}$ Lee, C. et al. 2005. Cohort Profile: The Australian Longitudinal Study on Women’s Health. Int. J. Epidemiol. 34(5): 987-991.

${ }^{13}$ Byles, J.E. 1999. Over the hill and picking up speed: A profile of older women of the Australian Longitudinal Study on Women’s Health. Australasian Journal on Ageing. 18(3 supp): 55-62.

${ }^{14}$ Ware, J.E. \& Sherbourne, C.D. 1992. The MOS 36-item Short Form Health Survey (SF-36): I. Conceptual framework and item selection. Medical Care. 30: 473-483

${ }^{15}$ Ware, J.E., Kosinski, M. \& Keller, S.K. 1994. SF-36® Physical and Mental Health Summary Scales: A User's Manual. The Health Institute. Boston, MA.

16 Haywood, K.L., Garrat, A.M., \& Fitzpatrick, R. 2005. Quality of life in older people: a structured review of generic self-assessed health instruments. Qual. Life Res. 14: 1651-68.

17 Stewart, A.L. \& Ware, J.E. 1992. Measuring functioning and well being: the Medical Outcomes Study Approach: 375-6. Duke University Press. Durham, NC. 
18 Schein, R.L. \& Koenig, H.G. 1997. The Center for Epidemiological Studies-Depression (CES-D) Scale: assessment of depression in the medically ill elderly. Int. J. Geriatr. Psych. 12: 436-46.

19 Lipski, P.S. 1996. Australian nutrition screening initiative. Aust. J. Ageing. 15: 14-6.

${ }^{20}$ Goodger, B et al. 1999. Assessment of a short scale to measure social support among older people. Aust. NZ. J. Pub. Hlth. 23: 260-5.

21 Suurmeijer, T.P.B.M. et al. 1995. The measurement of social support in the European research on incapacitating diseases and social support: the development of the social support questionnaire for transactions (SSQT). Soc. Sci. Med. 40: 1221-9.

22 Pollock, S.E. \& Duffy, M.E. 1990. The health-related hardiness scale: development and psychometric analysis. Nurs. Res. 39: 218-22.

${ }^{23}$ Byles, J. et al. 2006. Older Australian Women: Ageing in Urban, Rural and Remote Environments. Aust. J. Ageing. 25(3): 151-157.

24 Lucke, J. et al. 2007. Trends in women's risk factors and chronic conditions: Findings from the Australian Longitudinal Study on Women's Health. A. Women’s Health. In Press.

25 National Health and Medical Research Council. 2001Australian Alcohol Guidelines: Health Risks and Benefits. NHMRC. Canberra, ACT.

${ }^{26}$ Young, A.F., Powers, J.R. \& Bell, S.L. 2006. Attrition in longitudinal studies: Who do you lose?. Aust. NZ. J. Pub. Hlth. 304: 353-361.

27 Byles, J.E. et al. 2006. A drink to healthy ageing: outcomes associated with recommended, harmful and hazardous levels of alcohol use for older women. J. Am. Geriatric. Soc. 54(9): 1341-1347.

${ }^{28}$ Mishra, G.D. 2004. Do socio-economic gradients in women's health widen over time and with age? Soc. Sci. Med. 58: 1585-1595.

${ }^{29}$ Sibbritt, D.W., Byles, J.E. \& Regan C. 2007. Factors associated with decline in physical function in a cohort of older women. Age and Ageing. Doi: 10.1093/ageing/afm017.

30 Doll, R. et al. 1994. Mortality in relation to smoking: 40 years' observations on male British doctors. B. Med. J. 309: 901-11.

${ }^{31}$ World Health Organization. 2000. Obesity: preventing and managing the global epidemic. Report of a WHO consultation. World Health Organization Technical Report Series. Report No.: 894 i-xii, 1-253.

32 Tucker, K.L. et al. 2005. Baltimore Longitudinal Study of Aging. The combination of high fruit and vegetable and low saturated fat intakes is more protective against mortality in aging men than is either alone: the Baltimore Longitudinal Study of Aging. J. Nutr. 135: 556-561.

33 Mathers, C. 1999. Health differentials among older Australians. Health Monitoring Series No. 2. Australian Government Publishing Service. Canberra, ACT. 
${ }^{34}$ Boult, C. et al. 1996. Decreasing disability in the 21st century: The future effects of controlling six fatal and nonfatal conditions. Am. J. Pub. Hlth. 86(10):1388-1393. 